\title{
DUKUNGAN SUAMI TERHADAP IBU HAMIL YANG MENGALAMI EMESIS \\ (Desa Pangkalan Tiga)
}

\author{
${ }^{1}$ Isnina \\ ${ }^{1}$ STIKes Borneo Cendekia Medika \\ ${ }^{1}$ Email nina_mjk01@yahoo.co.id
}

\begin{abstract}
ABSTRAK
Mual dan muntah saat hamil sering dianggap sebagai hal biasa yang sering dibiarkan suami karena tidak tahu apa yang harus dilakukan ketika menghadapi emesi gravidarum. Berdasarkan studi pendahuluan di desa pangkalan tiga pada 5 November 2019 pukul 09.20 WIB kepada 15 suami yang memiliki istri hamil dimana 10 suami kurang memperhatikan keluhan istri untuk menangani emesis gravidarum. Tujuan penelitian ini untuk mengetahui dukungan suami terhadap wanita hamil yang mengalami emesis di Desa Pangkalan Tiga.

Desain penelitian yang digunakan adalah deskriptif. Populasi adalah suami ibu hamil trimester I di Desa pangkalan tiga. sejumlah 27 orang dengan menggunakan total sampling. Variabel yang diteliti adalah dukungan, suami, wanita hamil, emesis. Pengumpulan data yang digunakan adalah kuesioner, dan analisis data dengan mengedit, coding, scoring dan tabulasi

Hasil penelitian dukungan suami terhadap wanita hamil yang emesis di Desa pangkalan tiga. diketahui bahwa 27 responden menunjukkan sebagian besar dari mereka memiliki dukungan kurang 18 responden $(66,6 \%)$, sedangkan 8 responden $(29,7 \%)$ menunjukkan dukungan yang cukup dan 1 responden $(3,7 \%)$ menunjukkan dukungan yang baik

Berdasarkan hasil penelitian dapat disimpulkan bahwa sebagian besar dukungan suami terhadap wanita hamil yang mengalami emesis menunjukkan kurang dukungan

\section{HUSBAND'S SUPPORT TO PREGNANT WOMAN THAT HAVING EMESIS (Study in Pangkalan Tiga Village)}

\begin{abstract}
Nausea and vomiting while pregnant often supposed as usual thing that husband often let because doesn't know what must be done when facing emesi gravidarum. Based on preliminary study in pangkalan tiga village on 5 November 2019 at 09.20 WIB to 15 husbands that have pregnant wives where 10 husbands less of paying attention to wives complaints to handle emesis gravidarum. The purpose of this research to know husband's support to pregnant woman that having emesis in Pangkalan Tiga Village.

Research design used is descriptive. Population are husbands of pregnant women trimester I in pangkalan tiga Village. a number of 27 persons by using total sampling. Variable researched is support, husband, pregnant woman, emesis. Data collecting used is questionnaire, and data analysis by editing, coding, scoring and tabulating
\end{abstract}


Research result of husband's support to pregnant woman that having emesis in pangkalan tiga Village. knwn that 27 respondents show most of them have less support 18 respondents $(66,6 \%)$, while 8 respondents $(29,7 \%)$ show sufficient support and 1 respondent $(3,7 \%)$ shows good support

Based on research result can be concluded that most of husband's support to pregnant woman that having emesis shows less support

Keywords : Support, Husband, Pregnant woman, Emesis

\section{PENDAHULUAN}

Pada awal kehamilan mual muntah merupakan hal yang sangat menakutkan bagi ibu hamil. Hal ini sering menyebabkan menurunnya nafsu makan dan kurangnya asupan makanan yang sehat. Mual dan muntah saat hamil sering dianggap hal wajar dan sebagai sebuah konsekuensi normal di awal kehamilan tanpa diakui dampak hebat yang ditimbulkannya pada wanita dan keluarga mereka (Tiran, 2009). Suami pun sering membiarkan karena tidak tahu apa yang harus dilakukan ketika menghadapi emesi gravidarum. Dukungan suami terhadap kahamilan ibu akan berpengaruh terhadap peran suami dalam mengatasi emesis. Hal ini disebabkan karena suami tidak banyak yang menyadari bahwa terjadi tuntutan kebutuhan psikologis yang meningkat pada ibu hamil. Dalam arti perasaan tidak nyaman pada ibu hamil tersebut merupakan keinginan untuk lebih diperhatikan suami (Eko, 2011).

Hasil penelitian (Survika, 2008) di Surabaya tentang pengaruh keikutsertaan masyarakat khususnya suami dan orang tua dengan praktik ibu dalam pelayanan antenatal $l$ didapatkan bahwa variable peran suami mempunyai kemungkinan $42,5 \%$ lebih erat dibandingkan dengan peran oarng tua yang hanya 18,6\% terhadap praktik ibu dalam melakukan antenatal care dan mendeteksi tanda bahaya kehamilan (Dinkes Jatim, 2009).
Hasil penelitian yang dilakukan oleh (Saidah, 2014) terhadap 66 responden dapat dilihat tingkat kecemasan suami dalam menghadapi morning sickness ibu hamil trimester 1 diwilayah kecamatan ciputat timur lebih banyak mengalami kecemasan ringan yaitu sebanyak 40 responden $(60,6 \%)$, cemas sedang 22 responden $(33,3 \%)$, cemas berat 4 responden $(6,1 \%)$ dan panik tidak ada. Hasil capaian indikator ANC dapat dilihat dari cakupan K1 dan K4. Tahun 2012 di indonesia cakupan K1 mencapai 96,84\% data Kabupaten kotawaringin barat 2012 di Puskesmas pangkalan lada terdapat cakupan K1 sebanyak 96,73\% sedangkan pada tahun 2013 cakupan K1 sebanyak $101,41 \%$ sehinga dari tahun 2012 ke tahun 2013 mengalami peningkatan. Beradasarkan hasil studi pendahuluan yang di Polindes Ny. Kartikowati Desa pangkalan tiga Tanggal 5 November 2019 kepada 10 suami yang memiliki istri hamil didapatkan bahwa 10 suami kurang memperhatikan keluhan istri dalam mengatasi emesis gravidarum istrinya. Dan 5 suami memperhatikan keluhan istri dalam mengatasi emesis gravdarum istrinya.

Mual dan muntah selama kehamilan biasanya disebabkan oleh perubahan dalam system endokrin yang terjadi selama kehamilan, terutama disebabkan oleh tingginya fruktuasi kadar HCG (Human Chorionic Gonadotrphin), khususnya karena periode mual atau muntah 
gestasional yang paling umum adalah pada 12-16 minggu pertama. Saat itu HCG melewati kontrolovarium di hipofisis dan menyebabkan korpusluteum terus memproduksi estrogen dan progesterone, suatu fungsi yang nantinya diambi lalih oleh lapisan korionik plasenta. HCG dapat dideteksi dalam darah wanita dari sekitar 3 minggu gestasi (yaitu satu minggu setelah fertilisasi) (Tiran, 2009). Kurangnya peran suami terhadap kondisi ibu disebabkan karena suami sibuk bekerja, sehingga tidak mempunyai banyak waktu bersama ibu. Akibat kurangnya peran suami dapat menyebabkan istri akan lemah secara mental untuk menghadapi segala kondisi kehamilannya yang akan menimbulkan stress berkelanjutan selama masa kehamilannya (Vemale.com 2007).

Upaya dalam membentuk dukungan untuk lebih meningkatkan dalam mengatas emesis gravidarum diintensifkan dengan memberikan konseling kepada suami (karena suami adalah keluarga terdekat ibu.) saat pertama kali ANC (K1) bahwa kondisi yang dialami istrinya saat ini sangat memerlukan perhatian dan motivasi orang-orang terdekat, terutama suami, dalam membangun situasi yang nyaman serta dukungan moral bagi ibu yang dapat mengurangi rasa khawatir ibu. Memberikan Informasi yang efektif tentang pentingnya dukunga suami dan keluarga, serta memberikan edukasi tentang cara mengatasi emesis gravidarum pada ibu hamil sehingga dapat meningkatkan pengetahuan suami tentang emesis gravidarum. Jika suami tahu tentang emesis gravidarum diharapkan dukungan positif suami dalam mengatasi emesis gravidarum pada ibu hamil dan akan mendampinginya sehingga kehamilan berjalan normal. (Dina Bakrie, 2014). Berdasarkan uraian diatas penelitian tertarik untuk mengadakan penelitian tentang "Dukungan suami terhadap ibu hamil yang mengalami emesis". Tujuan penelitian yaitu mengetahui dukungan suami terhadap ibu hamil yang mengalami emesis di Desa pangkalan tiga. Manfaat penelitian secara teoritis yaitu penelitian ini dapat menambah bahan pustaka terkait dengan asuhan kebidanan, khususnya asuhan kehamilan mengenai dukungan suami terhadap istri yang mengalami emesis gravidarum. Secara praktis yaitu hasil penelitian ini dapat dijadikan masukan bagi bidan dalam memberikan KIE saat kunjungan K1, dijadikan referensi bagi pembaca lain yang ingin mengadakan penelitian lebih lanjut, serta dapat dijadikan masukan bagi program studi kebidanan STIkes BCM Pangkalan Bun untuk menambah referensi pengembangan proses belajar mengajar.

\section{BAHAN DAN METODE}

Penelitian ini dilakukan di Desa pangkalan tiga pada bulan januari sampai maret 2016 . Desain penelitian yang digunakan dalam penelitian ini adalah deskriptif, dimana penelitian hanya ingin mengetahui dukungan suami terhadap ibu hamil yang mengalami emesis di Desa pangkalan tiga. Penelitian deskriptif ini menggunakan pendekatan survey yaitu suatu cara penelitian deskriptif yang dilakukan terhadap sekumpulan obyek yang biasanya banyak dalam jangka waktu tertentu.(Notoatmodjo, 2010).

Populasi penelitian adalah keseluruhan objek penelitian atau objek yang diteliti (Notoatmodjo, 2010). Pada penelitian ini populasinya adalah seluruh suami ibu hamil trimester I yang ada di Desa pangkalan tiga.

Sampel adalah objek yang diteliti dan dianggap mewakili seluruh populasi (Notoatmodjo, 2010). Sampel yang di ambil yaitu seluruh suami ibu hamil trimester I sebanyak 27 sampel. 
Sampling adalah teknik dalam Instrumen yang digunakan dalam pengambilan sampel (Notoatmodjo, 2010). penelitian ini adalah kuesioner. Kuesioner Pada penelitian ini pengambilan sampel adalah suatu cara pengumpulan data yang secara total sampling.

Definisi operasional adalah uraian tentang batasan variabel yang dimaksud, atau tentang apa yang diukur oleh variabel yang bersangkutan (Notoatmodjo, 2010).

Tabel 4.1 Definisi operasional pola menstruasi pada akseptor KB suntik 3 bulan di Desa pangkalan tiga.

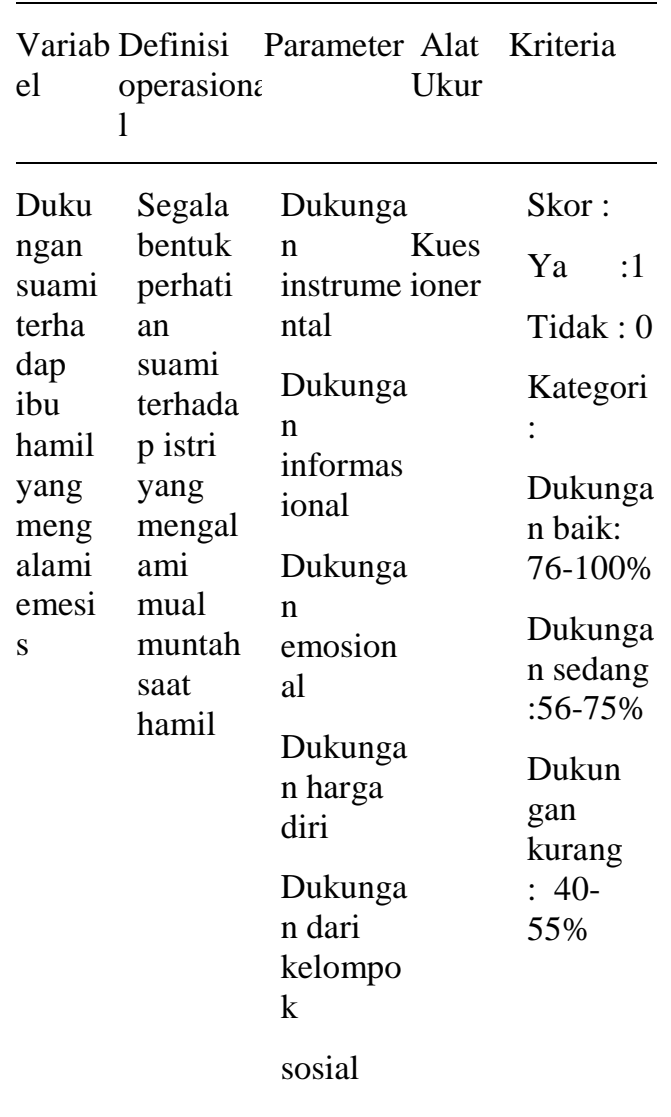

Instrumen penelitian adalah alat pada waktu penelitian dengan menggunakan suatu metode (Arikunto, 2010 ). Instrumen yang digunakan dalam penelitian ini berupa kuesioner yaitu sejumlah pernyataan tertulis yang digunakan untuk memperoleh data dan informasi dari responden dalam arti laporan tentang pribadinya, atau hal-hal yang responden ketahui. dilakukan dengan mengedarkan daftar suatu pertanyaan yang berupa formulirformulir kepada sejumlah subyek untuk mendapat tanggapan, informasi, jawaban, dan sebagainya (Notoadmodjo, 2007).

Cara pengambilan data yaitu menggunakan kuesioner yang dibagikan kepada responden. Sebelum mengisi kuesioner responden diberi penjelasan tentang cara mengisi angket, penyebaran ini dilakukan secara serentak dan setelah diisi angket ditarik kembali oleh peneliti kemudian dilakukan analisa data.

\section{HASIL}

Data umum

Karakteristik Responden Berdasarkan Usia Tabel 5.1 Distribusi frekuensi responden berdasarkan usia di Desa pangkalan tiga tahun 2019.

\begin{tabular}{ccc}
\hline Usia & Frekuensi & $\begin{array}{c}\text { Presentase } \\
(\%)\end{array}$ \\
\hline$<20$ tahun & 0 & 0 \\
$\begin{array}{c}20-35 \\
\text { tahun }\end{array}$ & 19 & 51,4 \\
$\geq 35$ tahun & 8 & 29,6 \\
\hline Jumlah & 27 & 100 \\
\hline
\end{tabular}

Sumber : Data Primer 2019

Berdasarkan tabel 5.1 dapat disimpulkan bahwa dari 27 responden hampir seluruhnya berusia 20-35 tahun yaitu sejumlah 19 responden $(51,4 \%)$.

Karakteristik Responden Berdasarkan pendidikan terakhir 
Tabel 5.2 Distribusi frekuensi responden berdasarkan pendidikan terakhir di Desa pangkalan tiga tahun 2019.

\begin{tabular}{ccc}
\hline Pendidikan & Frekuensi & $\begin{array}{c}\text { Prosentase } \\
(\%)\end{array}$ \\
\hline SD / MI & 4 & 14,8 \\
SMP / MTs & 8 & 29,7 \\
SMA / MA & 9 & 33,3 \\
PT & 6 & 22,2 \\
\hline Jumlah & 27 & 100 \\
\hline
\end{tabular}

Sumber : Data Primer 2019

Berdasarkan tabel 5.2 dapat disimpulkan bahwa dari 27 responden hampir setengahnya berpendidikan tingkat SMA / MA yaitu sejumlah 9 responden $(33,3 \%)$.

Karakteristik Responden Berdasarkan Pekerjaan

Tabel 5.3 Distribusi frekuensi responden berdasarkan pekerjaan di Desa pangkalan tiga tahun 2019.

\begin{tabular}{ccc}
\hline Pekerjaan & $\begin{array}{c}\text { Frekuen } \\
\text { si }\end{array}$ & $\begin{array}{c}\text { Prosentase } \\
(\%)\end{array}$ \\
\hline PNS & 7 & 8,1 \\
Pegawai & 14 & 44,4 \\
Swasta & 6 & 22,2 \\
Petani & 2 & 7,5 \\
Wiraswasta & & \\
\hline Jumlah & 27 & 100 \\
\hline
\end{tabular}

Sumber : Data Primer 2019

Berdasarkan tabel 5.3 dapat disimpulkan bahwa dari 27 responden hampir setengahnya bekerja sebagai pegawai swasta yaitu sejumlah 12 responden $(44,4$ $\%)$.
Karakteristik Responden Berdasarkan Informasi yang diperoleh

Tabel 5.4 Distribusi frekuensi responden berdasarkan informasi yang diperoleh di pangkalan tiga tahun 2019.

\begin{tabular}{ccc}
\hline $\begin{array}{c}\text { Mendapatkan } \\
\text { Informasi }\end{array}$ & Frekuensi & $\begin{array}{c}\text { Persentase } \\
\%\end{array}$ \\
\hline Pernah & 21 & 77,8 \\
Tidak pernah & 6 & 22,2 \\
\hline Jumlah & 27 & 100 \\
\hline
\end{tabular}

Sumber: Data Primer 2019

Berdasarkan tabel 5.4 dapat disimpulkan bahwa dari 27 responden sebagian besar pernah mendapatkan informasi yaitu sejumlah 27 responden $(77,8 \%)$.

Karakteristik responden berdasarkan sumber informasi

Tabel 5.5 Distribusi frekuensi responden berdasarkan sumber informasi di Desa pangkalan tiga tahun 2019 .

\begin{tabular}{ccc}
\hline $\begin{array}{c}\text { Sumber } \\
\text { Informasi }\end{array}$ & Frekuensi & $\begin{array}{c}\text { Persentase } \\
(\%)\end{array}$ \\
\hline Nakes & 19 & 70,4 \\
Radio / tv & 1 & 3,7 \\
Internet & 1 & 3,7 \\
Tidak ada & 6 & 22,2 \\
\hline Jumlah & 27 & 100 \\
\hline
\end{tabular}

Sumber: Data Primer 2019

Berdasarkan tabel 5.5 dapat disimpulkan bahwa dari 27 responden sebagian besar mendapatkan sumber informasi dari tenaga kesehatan yaitu sejumlah 19 responden $(70,4 \%)$.

\section{DATA KHUSUS}

Data khusus berupa dukungan suami terhadap ibu hamil yang mengalami emesis di Desa pangkalan tiga. Dari penelitian 
terhadap 27 responden dengan menggunakan kuesioner didapatkan hasil sebagai berikut pada tabel berikut :

Tabel 5.6 Distribusi frekuensi responden dukungan suami terhadap ibu hamil yang mengalami emesis di Desa pangkalan tiga tahun 2019.

\begin{tabular}{ccc}
\hline Kriteria & Frekuensi & $\begin{array}{c}\text { Prosentase } \\
(\%)\end{array}$ \\
\hline Baik & 2 & 7,4 \\
Sedang & 10 & 37,1 \\
Kurang & 15 & 55,5 \\
\hline Jumlah & 27 & 100 \\
\hline
\end{tabular}

Sumber : Data Primer 2019

Berdasarkan Tabel 5.6 menunjukkan bahwa dukungan suami terhadap ibu hamil yang mengalami emesis di Desa pangkalan tiga hampir seluruhnya dukungannya kurang yaitu sejumlah 15 responden $(55,5 \%)$.

\section{PEMBAHASAN}

Berdasarkan tabel 5.7 menunjukan bahwa dukungan suami pada ibu hamil yang mengalami emesis sebagian besar dukungan suami kurang sejumlah 15 responden (55,55\%). Menurut hasil tabulasi data khusus, dari 5 parameter hasil penelitian dukungan suami terhadap ibu hamil yang mengalami emesis sebanyak 15 responden (55,55\%), dipengaruhi oleh beberapa faktor yaitu umur suami yang memiliki istri hamil trimester I $20-35$ tahun yaitu sejumlah 18 orang $(51,4 \%)$, pendidikan suami yang sebagian besar tamatan SMA yaitu sejumlah 9 orang $(33,3 \%)$, suami yang pekerjaannya swasta yaitu berjumlah 12 orang $(44,4 \%)$, sementara dalam hal ini sumber informasi yang pernah didapat dalam menjaga ibu hamil yang mengalami emesis dari 21 respnden $(77,8 \%)$ sebagian besar yaitu 19 orang $(70,4 \%)$, suami pernah mendapat informasi berasal dari tenaga kesehatan.

Parameter yang digunakan untuk mendukung suami pada ibu hamil yang mengalami emesis ada 5 yaitu dukungan instrumental, dukungan informasional, dukungan emosional, dukungan harga diri, dan dukungan dari kelompok sosial. Dengan 27 responden dari parameter dukungan istrumental berjumlah 4 soal dari keseluruhan jawaban yang menunjukkan dukungan kurang menurut pernyatan dukungan insrumental "saya melarang istri periksa kebidan karena keterbatasan biaya" yang menjawab ya hanya 15 responden $(55,5 \%)$, sedangkan tidak berjumlah 12 responden $(44,5 \%)$. Bentuk dukungan ini merupakan penyedian materi yang dapat memberikan pertolongan langsung seperti pinjaman uang, pemberian barang, makanan serta pelayanan. Sedangkan dukungan harga diri sejumlah 4 soal, jawaban yang menujukkan dukungan kurang, "saya malas setiap istri mual muntah saya membantu menggantikan pekerjaan rumah tangga", untuk parameter dukungan harga diri yang menjawab ya 14 respoden $(51,9 \%)$, sedangkan yang menjawab tidak 13 responden $(48,1 \%)$ Sedangkan parameter dari dukungan kelompok sosial sejumlah 4 soal jawaban yang sesuai dengan pernyataan "Setiap istri mual muntah saya membantu menggantikan pekerjaan rumah tangga", bentuk dukungan ini berupa penghargaan positif pada individu, pemberian semangat, persetujuan dan pendapat individu, perbandingan yang positif dengan individu lain. Bentuk dukungan ini membantu individu dalam membangun harga diri dan kompetensi. Ada 12 responden (44,4\%), menjawab ya sedangkan yang menjawab tidak ada 15 responden $(55,5 \%)$ menjawab 
tidak, bentuk dukungan ini akan membuat individu merasa anggota dari satu kelompok yang mempunyai kesamaan minat dan aktifitas sosial yang sama.

Dukungan suami pada ibu hamil yang mengalami emesis dipengaruhi oleh faktor pekerjaan suami yang sebagian besar adalah swasta / buruh seperti pada hasil penelitian tabel 5.3 di peroleh karakteristik responden yaitu berjumlah 12 orang $(44,4 \%)$. Dengan pekerjaan swasta atau buruh biasanya suami sering kali mengabaikan tentang dukungan dan perhatiannya pada ibu hamil yang mengalami emesis, sehingga suami kurang memperdulikan keadaan emosional ibu saat hamil, di karenakan responden sudah lelah dengan pekerjaannya. Seringkali responden juga mengabaikan tentang adanya penyuluhan dari tenaga kesehatan dengan alasan kesibukan pekerjaan sehingga responden kurang mengerti tentang bagaimana menjaga dan mendukung istrinya yang mengalami emesis. Bekerja pada umumnya merupakan kegiatan yang menyita waktu (wawan, 2010). Sedangkan menurut Mubarok (2007), lingkungan perkerjaan dapat di jadikan seseorang memperoleh pengalaman dan pengetahuan, baik secara langsung maupun tidak langsung. Pekerjaan seseorang mempengaruhi perilaku/sikap seseorang. Karena pekerjaan suatu kebutuhan manusia, sehingga bisa berkembang pola pikirnya ( Notoadmojo, 2003).

\section{KESIMPULAN DAN SARAN}

\section{KESIMPULAN}

Dukungan suami pada ibu hamil yang mengalami emesis di Desa pangkalan tiga sebagian besar adalah kurang mendukung.

\section{SARAN}

Bagi Bidan yaitu bagi tenaga kesehatan khusunya bidan diharapkan dapat memberikan KIE pada suami tentang gejala awal kehamilan khususnya emesis dan hiperemesis pada kehamilan. Bagi Institusi Pendidikan yaitu Hasil dari penelitian yang telah dilakukan ini dapat digunakan sebagai tambahan dibidang kepustakaan dalam bidang kesehatan, sebagai acuan serta dapat digunakan sebagai bahan penelitian selanjutnya. Bagi Peneliti Selanjutnya yaitu Diharapkan hasil penelitian yang telah dilakukan dapat digunakan sebagai dasar penelitian selanjutnya dengan jumlah sampel yang lebih banyak dan melanjutkan penelitian tentang emesis.

\section{DAFTARPUSTAKA}

Arikunto, Suharsimi. 2010. Prosedur Penelitian Suatu Pendekatan Praktek. Jakarta: Rineka Cipta.

Azwar, Saifudin. 2008. Sikap Manusia Dan Teori Pengukurannya. Yogyakarta: Pustaka Pelajar

Bakrie, Dina. 2014. Panduan Lengkap Untuk Ibu Hamil. http://panduanlengkap-untuk-ibuhamil.blogspot.com. Di akses tanggal 3 April 2014.

Bobak. Dkk. 2005. Keperawatan Maternitas. Jakarta: EGC.

Eko. 2011. Tips Menghindari Stress Saat

\section{Hamil.}

http://www.ijolumoet.info.com. Di akses tanggal 13 Februari 2013.

Hidayat, Alimul Aziz. 2010. Metode Penelitian Kesehatan Paradigma Kuantitatif. Surabaya: Health Books Publishing. 
Hidayat, Alimul Aziz. 2012. Metode Penelitian Kebidanan dan Teknik Analisa Data. Jakarta: Salemba Medika.

KESGA. Dinas Kesehatan Jombang. 2013

Manuaba, Ida Bagus Gde. 2010. Ilmu Kebidanan, Penyakit Kandungan dan Keluarga Berencana untuk Pendidikan Bidan. Jakarta: EGC.

Mochtar, R. 1998. Sinopsis Obstetri Operatif Obstetri Edisi Kedua Cetakan Pertama. Jakarta: EGC.

Mubarok, Wahit Iqbal. 2009. Ilmu Keperawatan Komunitas. Jakarta: Salemba Medika

Nolan. 2004. Kehamilan Dan Melahirkan. Jakarta: Arcan

Notoatmodjo, Soekidjo. 2010. Ilmu Perilaku Kesehatan. Jakarta: Rineka Cipta.

Prawirohardjo,Sarwono. 2009. Ilmu Kebidanan.Jakarta: Bina Pustaka.

Rusmi, Hidayatun. 2008. Motivasi. Jakarta: PT Graha Loka Offset.

Saifuddin, A 2006. Sikap manusia dan pengukurannya. Jakarta: Rineka Cipta.

Sulistyawati, Ari. 2009. Asuhan Kebidanan Pada Masa Kebidanan. Jakarta: Salemba Medika

Tiran. 2009. Mual Dan Muntah Kehamilan. Jakarta: EGC.

Varney. 2007. Buku Ajar Asuhan Kebidanan. Jakarta: EGC.

Yohana. 2008. Peran Suami Dalam Membantu Istri. http://www.infosehat.com. Diakses tanggal 02 April 2002. 